\title{
Microcontroller based LADAR System for Speed Detection
}

\author{
Hameed Hamada \\ Telecommunications Engineering Student \\ Caledonian College of Engineering, Muscat
}

\author{
Malathi B. N. \\ Senior Lecturer, Department of E \& CoE \\ Caledonian College of Engineering, Muscat
}

\begin{abstract}
Using the strong LASER beams rather than using the microwave frequencies in the vehicle speed detection applications is an effective idea because it takes the benefit from the stronger beam used in LASER. These stronger beams can give more strength in speed detection other than the normal microwave systems used nowadays. Here, the paper gives a new idea of speed detection devices with using the LASER beams. This designed system has the ability to detect the speed of the vehicle in the roads and the main highways and the places where the drivers can use of more speed while driving. The designed LADAR system is more reliable and results accurate.
\end{abstract}

\section{General Terms}

Speed detection, LASER, RADAR, LADAR.

\section{Keywords}

LASER, RADAR, LADAR, speedometer, speed detection.

\section{INTRODUCTION}

RADAR - Radio Detection and Ranging is one of the communication systems used in recent days. It is normally using microwave signals to detect and range the objects in the sky or in any other free places. Now, RADAR systems are widespread in most of the countries. RADAR systems came to existence since 1940s. Present days, RADAR applications are increasing every day as the continuous improvements of the technologies. The RADAR systems are commonly used in airplanes control towers to detect and control the movements of the airplanes. Also, it is used in the marines to detect and control the incoming and outgoing ships. It is also good to use by meteorologists to detect any weather status such as storms, thunder-storms and the other types of storms. The engineers are working everyday hardly to get high responses and accurate results to make the people's life easier. That is done when the engineers are coming up with new devices and technologies. With using the double LASER beams for car speed detection application, the RADAR systems are becoming more powerful devices with faster results. Moreover, the LASER beams have less number of sources of interference, which can reduce the power of the signal. That is due to the stronger light beam of the LASER than the microwave signals, which can affect in giving clearer needed data. There are few of the cons of using the LASER RADAR as a replacement for using the microwave RADAR systems. These limitations are the LASER speedometer device work efficiently in the fixed way as it constructed from 2 stations. Moreover, the small particulars in the air may slightly affect the results of the system.

\section{LITERATURE REVIEW}

There were some literatures which referred before starting the project work to take a good idea and to check the possibilities of getting the needed results. The first literature is a study on the LADAR applications, which shows some of the main applications can be used from the LADAR devices. The second study is on designing a LADAR system to show the objects on 2 dimensions. Third literature showed one of LADAR systems can be used to detect the car speed. The fourth literature presented one of the LADAR application which it detect and show the objects in three dimensions. Finally, a study on the FM-CW RADAR system, which is one of the devices used in the present time. All the literatures found are good literatures which they gave me the needed information about the laser radar, its applications, and its construction, designing and working principles of the laser radar system. This will give me the ability to continue my project work with starting the research on my technical project work which is about constructing of RADAR system using the LASER beam.

\section{PROPOSED SYSTEM}

\subsection{Block Diagram of the System.}

The block diagram of the system is shown below. It shows the main working principle of the whole system of the LASER RADAR.

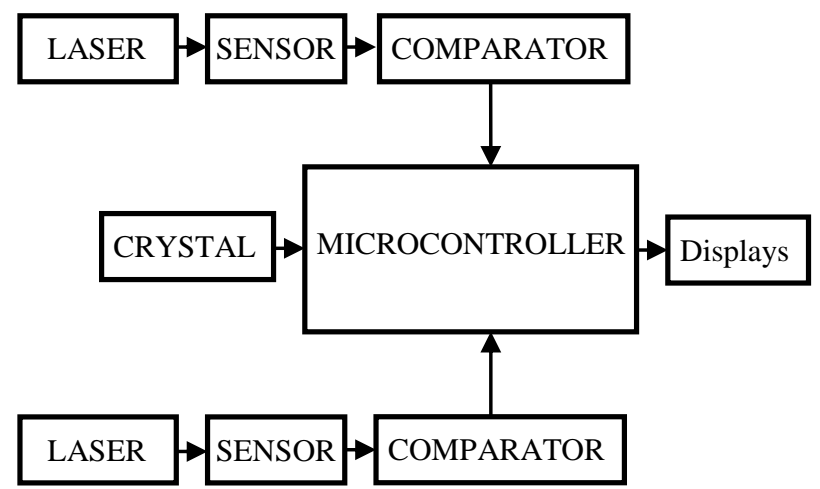

Figure 1: Block Diagram of the System

\subsection{Working Principle of the whole System}

In block diagram shown above, both lasers send their directed and concentrated light beam towards the light sensors. When the vehicle is coming and cutting the first laser beam, the comparator's output goes high and it informs the microcontroller, where, the microcontroller calculate the time till the second comparator output switching to high state. That 
is done when the second laser beam is cutting. After processing both data, the microcontroller is programmed to calculate the speed in $\mathrm{km} / \mathrm{h}$ and it is shown on the seven segment displays which will be switched on as its common directly connected to the supply voltage.

\subsection{Working Principle of Individual Parts}

This part of the paper is showing the main idea of the working principle of each components connected in the circuit to achieve the needed aim and objectives.

\section{Battery-}

It is a direct current (DC) voltage source which converts the chemical energy to electrical energy. Here, the needed battery is nine volts battery.

\section{IC 7805-}

It is an integrated circuit which is a voltage regulator, which it used to reduce the higher voltages to only positive 5 volts and keeps it regulated at that value. Here, it is used because the needed voltage is only 5 volts and the 9 volts battery will give more than the needed voltage value.

\section{AT89S52 microcontroller-}

It is a 40 pins CMOS integrated circuit used as microcontroller. It is high performance IC using a low power. It has an in-built flash memory of 8 kilo bytes size and 256 bytes random access memory. It has also four input/output (I/O) ports, which specified in eight bits per each port. It has also two pins for the inverting oscillator amplifier and built-in timer.

\section{7-segmant display-}

It is a display unit, which display the decimal formal of a number according to the incoming binary bits. It has two types: common anode 7-segmant display and common cathode 7-segmant display. The used type will be the common anode 7-segmant display which the common pins of it will be connected to the positive voltage supply (5 volts).

\section{LM 358-}

It is a single supply (from 3 Volts to 32 Volts) dual operational amplifier integrated circuit. It is also a shorted circuit outputs with low input bias current. Here, it is used as comparator, which mainly used to take the higher input and show it on its output.

\subsection{Design:}

This part is set to show the main design steps followed to achieve the main aim and objectives. The main designed parts of the system are the comparators and the speed finding.

The operational amplifier is designed as a comparator between the voltage across the variable resistance and the resistance of the light dependent resistor. 10 kilo ohms is an assumed value of the variable resistance.

For speed calculation, $\{\mathrm{s}=(\mathrm{d} / \mathrm{y}) * 3600\}$ formula is used. For speed in kilometers per hour (s) is used, $d$ is representing the distance which 10 kilometers of distance is chosen and (y) is the microcontroller timer value. Multiplying in 3600 is to show the speed in kilometers per hour.

\section{RESULTS AND DISCUSSION}

As the simulation done using PROTEUS software, the LADAR system has the ability to detect the speed of the vehicles and it can show the results on the seven segment displays. If any speed change found, the output also changes. The LASER RADAR system designed to show the speed of the cars in kilometers per hour $(\mathrm{km} / \mathrm{h})$, so it has the ability of detecting and showing the speed from $0 \mathrm{~km} / \mathrm{h}$ till $999 \mathrm{~km} / \mathrm{h}$. Here, some of the simulation results are stated in the following table:

Table 1. Samples of the Simulation Results.

\begin{tabular}{|c|c|}
\hline Try Number & Speed Detected $(\mathbf{k m} / \mathbf{h})$ \\
\hline 1 (initial) & 000 \\
\hline 2 & 054 \\
\hline 3 & 122 \\
\hline 4 & 153 \\
\hline 5 & 164 \\
\hline 6 & 196 \\
\hline
\end{tabular}

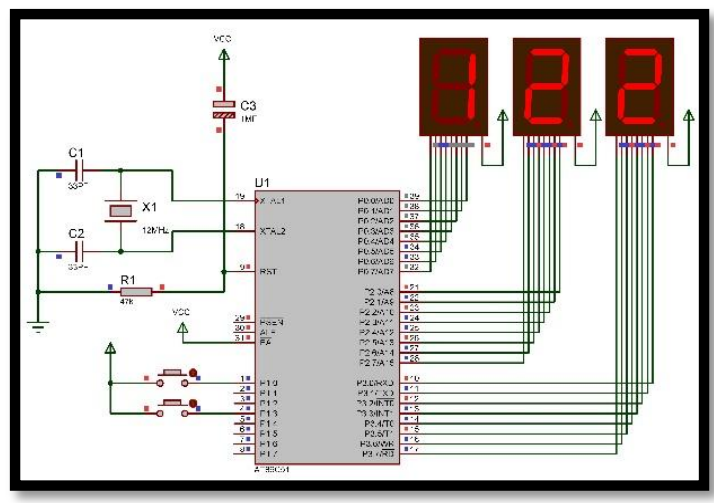

Figure 2: A Sample of Simulation of the Output Part

\section{CONCLUSION}

This paper is displaying one of the models of the speed detection devices with using LASER. The paper showed the proposed system design, the block diagram, working principle and the simulation results. The main idea of the working principle of the system is when the vehicle cuts the first laser beam, the microcontroller start to measure the time till the second laser beam is cut. Here, the microcontroller process the data and give the real speed on the seven segment display.

\section{ACKNOWLEDGMENTS}

The authors would like to give a special and great thanks for all the persons participate and give some help in this research and the project work. Special thanks for the authors that refereed for their papers.

\section{REFERENCES}

[1] Allisto, H, et al., 1993. Applications of laser radar. Sensor Review, 13/1, 26.

[2] Atmel. 2008. 8-bit Microcontroller with 8K Bytes InSystem Programmable Flash AT89S52. [ONLINE] Available at: http://www.atmel.com/images/doc1919.pdf. [Accessed 14 October 13]. 
[3] Blanquer, E., 2007. LADAR Proximity Fuze. M.Sc.. Stockholm, Sweden: KTH, Royal Institute of Technology.

[4] Cho, H., (2009). AIP CONFERENCE PROCEEDINGS. In International Conference of Computational Methods in Sciences and Engineering. United States, 25 - 30 September 2008. Melville, N.Y.: American Institute of Physics. 445 - 448.

[5] Mao, X., et al., 2012. Amplitude-Modulated Laser Radar for Range and Speed Measurement in Car Applications. Intelligent Transportation Systems, 13/1, 408 - 413.
[6] On Semiconductor. 2013. LM258, LM358, LM358A, LM2904, LM2904A, LM2904V, NCV2904, NCV2904V [ONLINE] Available at: http://www.onsemi.com/pub_lin k/Collateral/LM358-D.PDF. [Accessed 9 December 13].

[7] Wallace, A.M., et al., 2006. detecting and characterizing returns in a pulsed ladar system. Image Signal Process, $135 / 2,160-172$.

[8] Wikipedia, the free encyclopedia. 2013. Radar. [ONLINE] Available at: http://en.wikipedia.org/wiki/Radar. [Accessed 17 October 13]. 